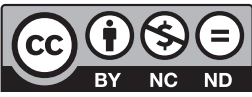

Estudos Teológicos foi licenciado com uma Licença Creative Commons Atribuição - NãoComercial - SemDerivados 3.0 Não Adaptada

http://dx.doi.org/10.22351/et.v60i3.4152

\title{
A dimensão prática no Pensamento de Melanchthon ${ }^{1}$
}

\author{
The practical dimension in Melanchthon's thought
}

\section{Eduardo Gross ${ }^{2}$}

Resumo: O presente estudo visa mostrar como a pesquisa recente sobre Melanchthon tem ressaltado a dimensão prática em seu pensamento para além da já antes amplamente reconhecida preocupação com a ética, que por isso não será discutida aqui diretamente. Apresentam-se resultados de pesquisas significativas sobre seu viés prático humanista enquanto princípio para a crítica da Escolástica, sobre o caráter existencial de sua perspectiva reformatória luterana e sobre a dimensão pedagógica de sua reflexão, entendida não no sentido de propostas educacionais concretas, mas como princípio interno que guia a reflexão em si. Para clarificação do conceito de prática parte-se da referência à distinção aristotélica entre práxis e poiesis feita por Vítor Westhelle.

Palavras-chave: Melanchthon. Prática. Práxis. Westhelle.

Abstract: This study aims to show how recent research on Melanchthon has stressed the practical dimension in his thought, beyond the former already recognized concern about ethics, which therefore will not be discussed here directly. It presents results of significant researches on his humanistic practical bias as critical principle against Scholasticism, on the existential character of his Lutheran reformatory perspective and about the pedagogical dimension of his reflection, understood not in the sense of concrete educational proposals, but as internal principle which guides the reflection itself. For a clarification of the concept of practice it uses Vitor Westhelle's reference to the Aristotelian distinction between praxis and poiesis.

Keywords: Melanchthon. Practice. Praxis. Westhelle.

\section{Teoria, práxis e poiesis}

O acento na dimensão prática tem sido uma reivindicação constante na reflexão latino-americana, particularmente no âmbito teológico influenciado pela teologia da libertação. Mas nem sempre o que se entendia por prática tinha um significado

1 O artigo foi recebido em 06 de outubro de 2020 e aprovado em 04 de dezembro de 2020 com base nas avaliações dos pareceristas ad hoc.

2 Doutor. UFJF, Juiz de Fora, MG. E-mail: eduardo.gross@ufjf.edu.br 
convergente. A aplicação da distinção aristotélica entre teoria, práxis e poiesis ao tema por Vítor Westhelle merece ser tomada como ponto de partida para uma apreciação devida do pensamento de Melanchthon a partir do contexto latino-americano. Quem teve a oportunidade de conviver com Westhelle e assistir a suas preleções sabe da importância de suas menções a essa distinção, discutida, por exemplo, no capítulo 8 de seu livro O Deus escandaloso: O uso e abuso da cruz, em Clashes of Confession: The Case of Latin America in a Global Context e em Pressupostos e implicações do conceito de práxis em Hugo Assmann. ${ }^{3}$ Primeiro, cabe mencionar a necessidade de conceber a inter-relação entre essas três atividades que caracterizam a ação humana, de modo a evitar uma compartimentalização que degrada cada uma delas. ${ }^{4}$ Em segundo lugar, o que aqui precisa de um destaque especial, é preciso distinguir entre dois tipos de prática, expressos pelos termos práxis e poiesis. O primeiro tipo indica ação performativa, ação que é ela mesma o resultado prático do que se faz - aqui se compreende tanto a prática discursivo-comunicativa quanto a ética. O segundo especifica o tipo de ação que resulta em determinado produto - sendo próprio para designar a esfera técnica ou a arte literária, por exemplo. Particularmente no âmbito da teologia da libertação, entretanto, a própria atividade libertária foi entendido como práxis. Isso é paralelo à diferença terminológica existente entre Habermas e Marx. Habermas reserva o termo práxis para a dimensão comunicativa, política, uso também da teologia política norte-atlântica, o que acarretou certa incompreensão entre esta e a teologia da libertação. Ainda que Westhelle mostre compreensão para razões contextuais, sua intenção com a recuperação da distinção aristotélica é, por um lado, evitar um antagonismo entre essas duas correntes de pensamento e, por outro, valorizar tanto a dimensão da ação discursiva pública, expressa por práxis, quanto a ação criativa que se manifesta na esfera da arte, sempre tão presente na reflexão teológica efetuada por ele, expressa por poiesis. ${ }^{5}$

Assim, a apresentação da dimensão prática do pensamento de Melanchthon que segue diz respeito ao que Westhelle chama de práxis: a dimensão prática que, primeiro, integra o próprio processo reflexivo e, segundo, enfatiza o aspecto discursivo e dialogal. Não está em exame, pois, a dimensão prática no sentido poiético, significativa na atividade de Melanchthon no âmbito dos estudos humanísticos literários ${ }^{6}$ e enquanto efetivador de projetos de reestruturação educacional. ${ }^{7}$ Uma discussão da aplicação feita

3 WESTHELLE, Vítor. Clashes of Confession: The Case of Latin America in a Global Context. Currents in Theology and Mission, v. 34, n. 4, p. 293-300, Aug. 2008a; WESTHELLE, Vítor. Uma "teoria" da cruz. As artes humanas: poiesis, praxis e theoria. In: O Deus escandaloso: O uso e abuso da cruz. São Leopoldo: EST; Sinodal, 2008b. capítulo 8; WESTHELLE, Vítor. Pressupostos e implicações do conceito de práxis em Hugo Assmann. Estudos Teológicos, v. 21, n. 1, p. 7-31, 1981.

4 WESTHELLE, 2008b, p. 135-136.

WESTHELLE, 2008b, p. 136-140; WESTHELLE, 1981, p. 9-11.

${ }^{6}$ Cf. GROSS, Eduardo. A apreciação de literatura no humanismo teológico de Filipe Melanchthon. Pandaemonium Germanicum, São Paulo: USP, v. 23, n. 41, p. 95-124, 2020.

7 Cf. BEISE ULRICH, Claudete; KLUG, João. Felipe Melanchthon (1497-1560): pedagogo da Reforma protestante, patrimônio da educação. Revista Brasileira de História das Religiões, Maringá: UEM, v. 8, n. 24, p. 149-170, jan./abr. 2016. 
por Westhelle, objetivando uma tipologia religiosa, da tríade teoria, práxis, poiesis em conexão com as dimensões de fé enquanto notitia, assensus e fiducia, que Melanchthon desenvolveu em seus Loci, também precisa ser deixada para outra oportunidade. ${ }^{8}$

\section{$O$ influxo do contexto humanista na dimensão prática da filosofia em Melanchthon}

O historiador Wilhelm Maurer, no contexto da exposição da relação intelectual do jovem Melanchthon com Erasmo, ressalta a importância dada já então à orientação prática do pensamento. Para ele, essa seria a razão para a preocupação dele com o aprofundamento da relação entre dialética e retórica. Caso a dialética seja desligada do âmbito prático, suas reflexões levam a quimeras e obscurecimento, daí a importância de sua relação com a retórica. Correspondentemente, a retórica degenera em mero falatório, caso ela deixe de considerar junto com a sua função prática o rigor reflexivo da dialética. De acordo com ele, a partir dessa perspectiva é que Melanchthon lê Aristóteles, ressaltando nesse processo a implicação ética da retórica. ${ }^{9}$

A apresentação sistematizada que Siegfried Wiedenhofer faz do jovem Melanchthon segue a mesma direção. ${ }^{10}$ Para ele, a avaliação de Melanchthon sobre a tradição anterior mostra a importância da perspectiva humanista e sua crítica à especulação rumo à valorização do aspecto prático. Nesse sentido, mostram-se como pontos importantes os exemplos da preocupação com a ética e com o âmbito jurídico. Mas, além de uma perspectiva filosófica, também a tomada de Cristo como modelo, em concordância com o humanismo do período, serve de base para tal direcionamento prático da reflexão. Na sua percepção, essa valorização da dimensão prática assumida do ideário humanista nunca foi deixada de lado. ${ }^{11}$ Por outro lado, a preocupação prática não implica diminuir a valorização do rigor cognitivo. E nesse sentido Wiedenhofer vê uma distinção em relação à perspectiva adotada por Erasmo, à medida que Melanchthon valoriza mais do que aquele a certeza no processo de conhecimento. Isso fica demonstrado com o fato de em seu caso a dialética vir a ser mais intimamente correlacionada com a retórica e receber assim uma apreciação mais positiva do que em Erasmo. Desse modo o processo pedagógico, em que para Melanchthon a retórica está implicada, pode superar o meramente provável em direção à certeza. Simultaneamente, com uma aplicação retórica, a dialética pode produzir um conhecimento que revele sentido existencial. ${ }^{12}$ Também William Weaver aponta para a relação com o pensamento de Erasmo ao destacar a importância da finalidade prática que

WESTHELLE, 2008a.

9 MAURER, Wilhelm. Der junge Melanchthon. Göttingen: Vandenhoeck \& Ruprecht, 1967-1969. 2 v. v. 1, p. 194-196.

10 WIEDENHOFER, Siegfried. Formalstrukturen humanistischer und reformatorischer Theologie bei Philipp Melanchthon. Bern: Herbert Lang; Frankfurt a. M.; München: Peter Lang, 1976. Teil 1: Text, p. 141-145.

11 WIEDENHOFER, 1976, v. 1, p. 313.

12 WIEDENHOFER, 1976, v. 1, p. 404-405. 
Melanchthon dá à reflexão. ${ }^{13}$ Nesse contexto, ele alerta que as diferenças de compreensão teológica devem ser claramente distinguidas da admiração que ele dedicava à retórica de Erasmo. ${ }^{14}$ Esse tipo de observação é importante também para mostrar como uma abordagem exclusivamente confessionalista ou polêmica, que muitas vezes procura acentuar o contraponto entre Melanchthon e Erasmo, obscurece nuances fundamentais.

Timothy Wengert destaca que já os Loci de 1535, em função dos desenvolvimentos históricos dos anos anteriores, demonstram uma preocupação explícita com a desvalorização da ética em função de uma compreensão antinomista da graça e da liberdade cristã. Por isso Melanchthon insiste na importância de se compreender a obediência da lei como uma consequência da graça. É essa que possibilita uma vida agradável a Deus, ainda que a lei não chegue nunca a ser cumprida integralmente. Mas essa impossibilidade não pode dar ocasião ao desprezo puro e simples da lei. Nesse contexto, a questão da obediência civil recebe destaque. ${ }^{15}$ Numa direção semelhante pode ser entendida a afirmação de Wiedenhofer, quando assevera haver até mesmo uma acentuação da preocupação ética no período do engajamento de Melanchthon na Reforma, ainda que ele já tivesse destacado a importância da dimensão prática de um modo geral anteriormente. ${ }^{16}$

Os estudos mais recentes de Günter Frank sobre a compreensão metodológica de loci e sobre a retórica em Melanchthon apontam de modo destacado para a importância da dimensão prática que ele apresenta, principalmente nos escritos filosóficos. Entretanto, já em seu primeiro livro sobre a filosofia de Melanchthon, a prática é apresentada como objetivo da sua reflexão. Ali se encontra o seu ideal de verdade para a filosofia. ${ }^{17}$ No Discurso sobre a Filosofia, de 1536, ele aponta a utilidade dessa disciplina para uma compreensão coerente do mundo e, a partir daí, para a construção de um discurso sistemático. Com isso se vai bem além do entendimento expresso nos Loci de 1521, ainda que com o resguardo de não dar espaço para a filosofia se colocar como instrumento fontal para o desenvolvimento teológico. ${ }^{18} \mathrm{O}$ mesmo também pode ser entendido quando Melanchthon critica o uso da linguagem pela escolástica. Para Frank, nesse caso não está em mira somente uma crítica ao uso de uma forma vulgar de latim, em lugar do clássico, mas principalmente uma finalidade ético-política do processo retórico-reflexivo. Do contrário, a filosofia se torna apenas um tipo de exercício lúdico. ${ }^{19}$

Particularmente quando trata da importância da dialética em conjunção com a retórica, Frank aponta para a correlação entre reflexão e prática. Fundamental, nesse

13 WEAVER, William P. Rhetorik. In: FRANK, Günter (Ed.). Der Reformator zwischen Glauben und Wissen. Ein Handbuch. Berlin: De Gruyter, 2017. p. 539.

${ }^{14}$ Cf. também ainda FRANK, Günter. Topische Dogmatik im Zeitalter der Konfessionalisierung: Philipp Melanchthon, Wolfgang Musculus, Melchor Cano. In: DINGEL, Irene; KOHNLE, Armin (Hrsg.). Philipp Melanchthon: Lehrer Deutschlands, Reformator Europas. Leipzig: Evangelische Verlagsanstalt, 2011. p. 259.

15 WENGERT, Timothy J. Human Freedom, Christian Righteousness: Philip Melanchthon's Exegetical Dispute with Erasmus of Rotterdam. New York; Oxford: Oxford University Press, 1998. p. 144.

16 WIEDENHOFER, 1976, v. 1, p. 493-494.

${ }_{17}$ FRANK, Günter. Die theologische Philosophie Philipp Melanchthons (1497-1560). Leipzig: Benno, 1995. p. 58.

18 FRANK, 1995, p. 67-69.

19 FRANK, 1995, p. 76. 
sentido, é sua exposição do desenvolvimento que ocorre no pensamento de Melanchthon sobre a relação entre essas artes. De uma forma geral, Melanchthon sempre manteve tal integração. Entretanto, o acento na retórica, que aparece em alguns textos, vai se modificando, de modo que se possa dizer que com o tempo, em sua exposição da retórica, vai havendo uma ênfase crescente na dimensão lógica, como Frank destaca em relação aos Erotemata dialectices de 1547. Ou seja, é importante perceber que a preocupação prática com a reflexão não se reduz simplesmente a uma retoricização da filosofia, uma vez que a dialética continua fundamental para manter o caráter rigoroso da argumentação. Sempre devem continuar valendo as regras do silogismo, de maneira que se possa invalidar discursos sofísticos. ${ }^{20}$ Fundamental, nesse contexto, por outro lado, é a mudança de paradigma filosófico em relação ao que se desenvolvia na Escolástica. Em lugar de uma filosofia do ser como a desenvolvida então, em consonância com o ambiente humanista em geral, Melanchthon privilegia uma filosofia prática em que a abordagem principal se dá em torno da linguagem e da história. Essa é a base a partir da qual a ética ganhará relevância. A fundamentação dessa perspectiva, por sua vez, Frank encontra na valorização da dimensão da subjetividade que a sua adoção da noção de ideias inatas lhe possibilitou. ${ }^{21}$

A apresentação que Hans-Peter Neumann faz do desenvolvimento da compreensão que Melanchthon tem de dialética vai numa direção semelhante. Para Neumann, Melanchthon parte de uma noção de dialética em que definição e estruturação da exposição têm relevo para uma posterior ênfase cada vez mais linguístico-discursiva, destacando uma dimensão pedagógica da dialética para por fim afirmá-la como ars artium, ou seja, como o instrumento cujo domínio permite conhecer - e, nesse sentido, como a disciplina que ensina a aprender e a ensinar. Conforme a ilustração terminológica do autor, Melanchthon passaria de uma ênfase em dicere e disserere para docere, sendo que o último momento, o dos Erotemata dialectices de 1547, é aquele em que o resgate do âmbito próprio da dialética chega a se manifestar mais fortemente -, embora nunca perca a sua a vinculação com o docere. Por outro lado, é importante observar que essa dimensão pedagógica da dialética é sempre compreendida também de modo reflexivo. A reflexão dialética é sempre simultaneamente voltada para os outros e para si mesmo. Nessa visão pragmática, a dialética é pensada como uma capacidade intrínseca do ser humano, uma lógica dotada por Deus que permite o conhecimento, com a lembrança de que se trata de um instrumento pedagógico, não de um fim em si. $^{22} \mathrm{O}$ desenvolvimento interno dessa concepção em Melanchthon ocorre a partir da reflexão anterior a que ele se conecta, no caso, a interpretação de Aristóteles via Cícero e Quintiliano, a crítica humanista à redução da dialética à lógica e a proposta do humanista Rodolfo Agricola, que tanto encantou o jovem Melanchthon. ${ }^{23}$ Além disso, Neumann descreve como características do contexto humanista compartilhadas por

${ }^{20}$ FRANK, 1995, p. 164-165.

${ }^{21}$ FRANK, 1995, p. 179-180.

22 NEUMANN, Hans-Peter. Dialektik. In: FRANK, Günter (Ed.). Der Reformator zwischen Glauben und Wissen. Ein Handbuch. Berlin: De Gruyter, 2017. p. 529-533.

${ }^{23}$ NEUMANN, 2017, p. 522. 
Melanchthon a valorização do momento da inventio, a relação com a retórica, a perspectiva existencial prática e a relação com as ciências da linguagem. ${ }^{24}$ Por fim, cabe mencionar aqui o lembrete de Neumann quanto à importância de recepção posterior de Melanchthon, que atinge até Christian Wolff e Leibniz, e cujos detalhes, segundo ele, ainda permanecem abertos à pesquisa. ${ }^{25}$

\section{Orientação existencial}

Bo Kristian Holm, tomando em auxílio um estudo de Risto Saarinen, remete a origem do conceito de beneficia, que se encontra nos Loci de 1521, à concepção de Sêneca, quando esse afirma a benevolência como o beneficium por excelência. A aplicação dessa noção a Deus permite superar uma concepção religiosa baseada no temor e pensar uma relação de proximidade. Como quer que seja - é preciso lembrar que a dimensão da lei e do temor a Deus está muito presente nos textos de Melanchthon -, o importante é que a função desse conceito nos Loci pretende reorientar a tarefa reflexiva de uma dimensão de conhecimento especulativo para a de um conhecimento que pode ser chamado de existencial, porque voltado para a relação vivencial dos fiéis com Deus e suas consequências práticas. A questão dos conteúdos da reflexão teológica se subordina à apropriação dessa dimensão experiencial. Tal orientação existencial se enquadra no âmbito da reflexão com ênfase prática que, como já se tem visto até aqui, caracteriza o humanismo. Aqui com um acento na percepção da experiência religiosa. ${ }^{26}$

Wolfgang Matz faz uma leitura da obra de Melanchthon que privilegia a dimensão teológica no seu pensamento. A partir de sua perspectiva, ele chega a afirmar que o conceito de beneficia seria o centro sistematizador dos Loci, e nisso se manifestaria a proximidade de Melanchthon em relação a Lutero. ${ }^{27}$ Em conexão com essa sua visão está a sua busca por mostrar como não se trata em Melanchthon de uma concepção ontológica da graça, como a que caracterizaria Tomás de Aquino, mas de uma concepção que ele denomina de "teológico-relacional"28. Ao sintetizar essa posição, reconhece que Melanchthon interligou a psicologia humanista com a teologia reformatória, mas interpreta que com o passar do tempo ele foi se tornando cada vez mais teológico. ${ }^{29}$ Parece um pouco difícil aceitar o conjunto dessa interpretação, uma vez que a dimensão filosófico-psicológica continuou presente em toda a trajetória de Melanchthon. Mesmo assim, a ênfase na relacionalidade enquanto dimensão fundamental da perspectiva teológica de Melanchthon mostra-se como um elemento a mais que demonstra o caráter prático existencial como central em seu pensamento. Entretanto, parece mais simples reconhecer que o aspecto que Matz denomina de relacional

\footnotetext{
${ }^{24}$ NEUMANN, 2017, p. 526.

25 NEUMANN, 2017, p. 519.

${ }^{26}$ HOLM, Bo Kristian. Theologische Anthropologie. In: FRANK (Ed.), 2017, p. 398.

27 MATZ, Wolfgang. Der befreite Mensch: Die Willenslehre in der Theologie Philipp Melanchthons. Göttingen: Vandenhoeck \& Ruprecht, 2001. p. 92-93.

28 MATZ, 2001, p. 189.

${ }^{29}$ MATZ, 2001, p. 191.
} 
seja compreendido como a expressão teológica da orientação prática que marca o humanismo em geral, e que se expressa então de forma existencial religiosa com a expressão luterana. Que esse aspecto esteja no escopo dos Loci o próprio Melanchthon o afirma, e que ele expresse um elemento central da teologia luterana também é claro. Entretanto, deixar de reconhecer a sua relação com o contexto humanista leva a uma compreensão menos profunda do conjunto da obra de Melanchthon.

Wilhelm Maurer aponta um elemento importante que representa uma contribuição específica de Melanchthon à compreensão dos beneficia Christi. A partir da preocupação histórica que caracteriza sua perspectiva, Melanchthon teria relacionado a experiência religiosa da justificação com a história da salvação. Deste modo, o fiel pode se inserir no processo do evento que se realiza em Cristo. ${ }^{30}$ No caso de Melanchthon, na prática a compreensão desse processo não se dá a partir de uma aflição pessoal íntima em relação à incapacidade de justificação diante de um Deus entendido como juiz inclemente - como tantas vezes se retrata o caso de Lutero. No seu caso, em função de uma base vivencial diversa, ele insere o evento de Cristo numa filosofia da história, que no seu caso se caracteriza pela dinâmica relacional entre lei e evangelho. ${ }^{31}$ Inserindo a doutrina da justificação no processo da história da salvação ele lhe conferiu, dessa forma, uma configuração própria em relação ao modo de exposição feito por Lutero. ${ }^{32}$

Também Wiedenhofer, ao sistematizar o pensamento inicial de Melanchthon, enfatiza sua correspondência com o aspecto existencial do humanismo em geral. Por um lado, destaca que a valorização da Escritura se ligava tanto à busca filológica do texto original quanto à apropriação interior, pessoal, da mensagem textual. Além disso, a teologia era entendida como voltada à dimensão prática tanto no que se refere à esfera ética quanto à reorganização dos afetos interiores. ${ }^{33}$ Que o ambiente do humanismo tenha sido central para esse desenvolvimento, ele expressa a partir das seguintes características que moldam tal ambiente: “[...] com sua ideia da formação humana, sua relação específica com a linguagem e a história assim como a sua compreensão da Filosofia como uma sabedoria prática que visa o [sic] domínio da práxis vivencial individual e social" "34. A referência para tal é a valorização da cultura retórica, que, por sua vez, se caracteriza pela promoção do ecletismo. Em todo caso, toda a atividade teológica é vista por Melanchthon como prático-existencial. Tal dimensão não é entendida no sentido de uma aplicação do conhecimento que ocorre só num momento posterior como, por exemplo, na pregação -, mas ela engloba a atividade reflexiva em seu todo. ${ }^{35}$

${ }^{30}$ MAURER, 1969, v. 2, p. 348.

${ }^{31}$ MAURER, 1969, v. 2, p. 352.

${ }^{32}$ MAURER, 1969, v. 2, p. 358.

${ }^{33}$ WIEDENHOFER, 1976, v. 1, p. 154-156; cf. também MÜLLER, Ralf. Die Ordnung der Affekte: Frömmigkeit als Erziehungsideal bei Erasmus von Rotterdam und Philipp Melanchthon. Bad Heilbrunn: Julius Klinkhardt, 2017. capítulo 5.

34 “[...] mit seiner Bildungsidee, seinem eigentümlichen Sprach- und Geschichtsverhältnis, sowie seinem Verständnis der Philosophie als einer auf die Bewältingung individueller und gesellschaftlicher Lebenspraxis abzielender praktischer Weisheit." WIEDENHOFER, 1976, v. 1, p. 157.

35 WIEDENHOFER, 1976, v. 1, p. 406. 
Diante disso é relevante compreender essa dimensão religiosa existencial dentro do quadro que Günter Frank traça do desenvolvimento da crítica à especulação escolástica relacionado com a metodologia da tópica. Essa metodologia possibilitou uma crítica à ênfase na lógica, o que, por sua vez, reorientou a dialética rumo a uma perspectiva pragmática. ${ }^{36}$ Frank chama atenção para os significativos eventos históricos representados pelos entusiastas iconoclastas, pelo movimento anabatista e pela revolta dos camponeses. Esses fizeram com que a preocupação existencial interior do jovem Melanchthon também passasse a se expressar numa reflexão voltada para o exterior, para o âmbito comunitário, social e político, de modo que a ética ganhasse destaque. ${ }^{37}$ Importante, em todo caso, é que nesse processo ele procurou manter, com bastante rigor - a seu modo - a separação temática entre a filosofia e a teologia. Os temas teológicos não se tornam objeto de análise por parte da filosofia e a ética se restringe ao âmbito (teologicamente delimitado) da lei, da exterioridade, que pode ser compreendida e julgada, ao menos em parte, a partir dos já referidos conhecimentos inatos, sendo que a compreensão profunda da existência humana fica reservada à teologia.

\section{Orientação pedagógica}

O direcionamento da atividade de Melanchthon para o âmbito pedagógico é amplamente reconhecido. ${ }^{38}$ Mesmo quem não vá tão longe quanto Maurer, que conclui de forma radical que Melanchthon não teve uma significação maior enquanto teólogo, mas sim enquanto reformador educacional ${ }^{39}$, sabe da importância que o aporte da tradição humanista representado por ele significou em termos pedagógicos, particularmente no âmbito sob influência da Reforma. No mínimo, seu papel enquanto questionador de grupos radicais contrários ao desenvolvimento da erudição é reconhecido, mesmo por quem não favoreça muito o aspecto humanista em sua teologia. ${ }^{40}$ Não que se possa chegar a dizer que Wengert desvalorize a dimensão humanista em Melanchthon. Mas ele procura enfatizar que essa não se deve a uma proximidade com o ideal erasmiano. Na sua interpretação, foi a distinção entre os âmbitos civil e religioso antecipada pela distinção entre lei e evangelho que, na verdade, favoreceu a dimensão humanista do pensamento de Melanchthon.

Em todo caso, a importância de Melanchthon para o desenvolvimento pedagógico é bem sintetizada por Walter Sparm ao expor sua influência no Sacro Império:

A concepção universal de Filosofia de Melanchthon [FRANK, 2012, p. 1-10] se tornou efetiva através das diretrizes acadêmicas elaboradas a partir do modelo de Wittenberg

\footnotetext{
${ }^{36}$ FRANK, Günter. Topische Dogmatik im Zeitalter der Konfessionalisierung: Philipp Melanchthon, Wolfgang Musculus, Melchor Cano. In: DINGEL; KOHNLE (Hrsg.), 2011, p. 257.

${ }^{37}$ FRANK, Günter. Praktische Philosophie. In: FRANK (Ed.), 2017, p. 459.

38 Cf. BEISE ULRICH; KLUG, 2016.

39 MAURER, 1969, v. 2, p. 511.

40 WENGERT, 1988, p. 94-95, 108, 146; cf. também WRIEDT, Markus. Bildung, Schule und Universität. In: FRANK (Ed.), 2017, p. 153.
} 
e de Marburg também na Filosofia prática, que era subdividida em Ética, Política (incluído o Direito Natural) e Economia (frequentemente, alemã). Ela também fortaleceu a Filosofia Natural, que se compunha de Física, Matemática avançada e Astronomia; ela era explicada a partir das fontes (Aristóteles, Galeno, Ptolomeu, Cícero) e complementada com autores contemporâneos. Este cânone de disciplinas permaneceu como regra no século $16^{41}$.

Markus Wriedt esclarece a diferenciação necessária entre o conceito de formação de Melanchthon e a concepção moderna. Seu conceito, afim ao de Erasmo, era o de que a formação visava tornar a pessoa aquilo que ela deveria ser enquanto imagem divina. Nesse sentido, cercear essa formação significa atentar contra a dignidade da pessoa. Isso já aponta para a interligação entre conhecimento e piedade que perpassa esse modelo, que engloba três dimensões: eruditio, scientia e sapientia ${ }^{42}$ Como peculiaridades que mostram a centralidade da preocupação com a dimensão pedagógica cabe referir a criação, na sua versão de ensino da retórica, de um novo gênero retórico, o didático ${ }^{43}$ e as suas imagens, tantas vezes repetidas, representando a igreja e a beatitude eterna como uma escola ou universidade. ${ }^{44}$

A ligação entre formação e piedade referida por Wriedt representa a preocupação central do recente estudo de Ralf Müller dedicado à dimensão pedagógica na reflexão de Melanchthon. Esse mostra como o aspecto da piedade é central para a concepção pedagógica humanista, uma vez que ela é considerada o meio de possibilitar o (re-)ordenamento dos afetos. Nesse sentido, para ele, não é possível pensar o desenvolvimento da pedagogia humanista à parte dos elementos cristãos que a constituíram. ${ }^{45}$ Em um período de grandes transformações tanto na sociedade quanto nas ideias, uma das principais preocupações era com a ordem. Nesse sentido, ganha importância a reflexão sobre o ordenamento interior dos afetos e sobre o ordenamento exterior da vida social. Isso se faz a partir de uma concepção de piedade que inclui tanto a experiência religiosa quanto a moralidade. Parte importante dessa reflexão na época diz respeito à origem divina desse reordenamento, através do modo como atua a graça no âmbito humano. ${ }^{46}$ Significativo na abordagem de Müller é o fato de que, mesmo que apresente em detalhe as especificidades que diferenciam a função pedagógica da piedade em Erasmo e Melanchthon, seu ponto de partida é que, no início do movimento da Reforma (ou seja, no período de atividade de Melanchthon), o modelo

41 "Die universale Philosophiekonzeption Melanchthons (Frank: Frank/Mundt 2012, 1-10) wurde durch die Studienordnungen nach Wittenberger und Marburger Vorbild auch in der praktischen Philosophie wirksam, die in Ethik, Politik (darin das Naturrecht) und (oft deutsche) Ökonomik gegliedert wurde. Sie verstärkte auch die Naturphilosophie, die als Physik, höhere Mathematik und Astronomie ausgelegt war; sie wurde aus den Quellen (Aristoteles, Galen, Ptolemaios, Cicero) erklärt und um zeitgenössische Autoren ergänzt. Dieser Fächerkanon blieb im 16. Jahrhundert die Regel [...].” SPARM, Walter. Altes Reich. In: FRANK (Ed.), 2017, p. 613.

42 WRIEDT, 2017, p. 141-147.

43 WRIEDT, 2017, p. 146.

44 WRIEDT, 2017, p. 149-152; WIEDERHOFER, 1976, v. 1, p. 286-292.

45 MÜLLER, 2017, p. 16, 18, 20.

${ }^{46}$ MÜLLER, 2017, p. 26-27. 
de educação proposto é basicamente humanista. Uma diferenciação confessionalista, conforme ele, teria ocorrido só num segundo momento. ${ }^{47} \mathrm{~A}$ convergência básica entre Erasmo e Melanchthon no que diz respeito aos ideais pedagógicos, para ele, é atestada na correspondência trocada entre eles. Em suas cartas, os aspectos teológicos que os separam não são tema abordado diretamente. Seguindo o padrão dos eruditos humanistas, eles acentuam de modo cortês a convergência de suas ideias no que diz respeito à importância da educação e da cultura letrada, assim como da sua ligação com a formação ética. ${ }^{48}$ Eles têm em comum a concepção de que só através dos estudos humanistas a pessoa pode se aproximar do ideal humano. ${ }^{49}$ Também Maurer observa a convergência pedagógica entre Melanchthon e Erasmo. Ele, entretanto, o faz a partir da função prática que se mostra no modelo humanista da metodologia dos loci. ${ }^{50}$

As peculiaridades da concepção pedagógica de Melanchthon se desenvolvem a partir da diferenciação entre lei e evangelho. De acordo com essa distinção, ele considera que há dois tipos de piedade: a divina e a humana. A piedade divina é resultado da ação da graça, enquanto que a humana se funda na lei natural, que, segundo Melanchthon, teria sido impressa nas mentes por ocasião da criação. ${ }^{51}$ Mas no desenvolvimento do seu pensamento ocorrem modificações também com relação à abordagem pedagógica. O determinismo que se encontra nos Loci de 1521 prejudica a elaboração de uma pedagogia dos afetos - afinal, é só a ordenação divina desses, por meio do Espírito Santo, que vai ser verdadeiramente significativa. ${ }^{52}$ Mais tarde, tendo como pano de fundo os distúrbios dos iconoclastas, essa posição se modifica, justamente para possibilitar a ação educativa que visa à preservação da cultura e da ordem social. ${ }^{53} \mathrm{Ou}$ seja, percebe-se aqui como a finalidade prático-pedagógica do seu ideário encaminha a modificação do pensamento de Melanchthon, favorecendo inclusive a resolução da contradição entre a postulação de uma lei natural e a incapacidade prática de o ser humano lidar satisfatoriamente com seus afetos. Müller, no entanto, apesar de também reconhecer isso, em sua interpretação de Melanchthon curiosamente mantém a prioridade da antropologia desenvolvida nos Loci de 1521 para a compreensão da pedagogia que se originou a partir do reformador. ${ }^{54} \mathrm{~A}$ consequência disso em seu livro é a acentuação de um aspecto mais autoritário da pedagogia que emergiria de Melanchthon. A ênfase na ordem social e a função aterradora da lei (em seu aspecto

${ }^{47}$ MÜLLER, 2017, p. 20, 28-30.

${ }^{48}$ MÜLLER, 2017, p. 63-73.

${ }^{49}$ MÜLLER, 2017, p. 24, 31-34.

${ }^{50}$ MAURER, 1967, v. 1, p. 205-206.

${ }^{51}$ MÜLLER, 2017, p. 123-126.

52 MÜLLER, 2017, p. 133-134.

${ }^{53}$ MÜLLER, 2017, p. 134-137; cf. FRANK, Günter. Praktische Philosophie unter den Bedingungen reformatorischer Theologie. Die Intellektlehre als Begründung der Willensfreiheit in Philipp Melanchthons Kommentaren zur praktischen Philosophie des Aristoteles. In: FRANK, Günter; LALLA, Sebastian (Hrgb.). Fragmenta Melanchthoniana. Band 1. Zur Geistesgeschichte des Mittelalters und der frühen Neuzeit. Heidelberg; Ubstadt-Weiher: Regionalkultur, 2003. p. 252s; FRANK, Günter. Einleitung. In: MELANCHTHON, Philipp. Ethicae Doctrinae Elementa et Enarratio Libri quinti Ethicorum. Günter Frank (Hrgb.). Stuttgart-Bad Cannstatt: Frommann-Holzboog, 2008. p. XXXIX.

${ }^{54}$ MÜLLER, 2017, p. 181-185. 
teológico), em sua opinião, poderiam levar a práticas pedagógicas que deixam pouco espaço para estilos pessoais menos adaptados à ordem convencional. Por outro lado, ele também reconhece que a base na teologia da graça tem a vantagem de possibilitar o desenvolvimento de uma pedagogia em que a pressão sobre a responsabilidade da pessoa quanto ao seu próprio melhoramento não seja exagerada. ${ }^{55}$ Esse tema seria muito interessante para uma investigação mais pormenorizada. Por um lado, Müller aponta para um problema importante que pode surgir a partir do modelo pedagógico melanchthoniano. Por outro lado, não deixa de causar estranheza o fato de, mesmo sabendo haver um desenvolvimento na concepção antropológica de Melanchthon, ele assumir de modo peremptório que é a configuração antropológica anterior que molda a pedagogia que resulta de suas concepções. Isso causa a desconfiança de que sua apresentação simplifica esquematicamente a contraposição que ele faz entre o modelo pedagógico de Melanchthon e o de Erasmo.

A centralidade do aspecto da linguagem na pedagogia de Melanchthon é amplamente reconhecida. Ela demonstra a interconexão do modelo pedagógico com a perspectiva retórica. A linguagem é o espaço de abertura da compreensão, sendo assim condição para a formação. ${ }^{56}$ Nesse sentido, ela é fundamental para a constituição da sociedade humana e para a compreensão do mundo. Sem o estudo e o aperfeiçoamento da linguagem, o conhecimento sofre uma decadência. A era medieval é apontada como um exemplo disso e essa decadência, por seu turno, repercute no âmbito da religião. A recuperação das artes da linguagem é, nesse sentido, apontada por ele como condição para o aprimoramento do conhecimento e do cultivo prático do cristianismo original. ${ }^{57}$ Com isso se percebe tanto a convergência do humanismo transalpino com pressupostos do Renascimento em geral quanto a sua peculiaridade quanto à ênfase no aspecto religioso da recuperação da cultura passada.

Wiedenhofer oferece uma síntese muito bem elaborada do desenvolvimento da visão de Melanchthon sobre ciência. Basicamente, trata-se de uma visão eclética, em que uma perspectiva platônica fundamental é desenvolvida com uma abordagem que valoriza a linguagem e a retórica, sendo acrescida de elementos aristotélicos. Não é dado espaço para a especulação metafísica, sendo Aristóteles interpretado primordialmente em função de objetivos práticos. É nesse sentido que Melanchthon elaborou uma superposição entre humanismo e elementos de aristotelismo. ${ }^{58}$ A valorização do estudo da História aparece como uma das contribuições de Melanchthon. Por mais que suas elaborações históricas fossem profundamente teológicas e, para os parâmetros modernos, bastante fantásticas, Wiedenhofer enfatiza o fato de que Melanchthon forneceu um impulso inicial muito importante com a sua reivindicação de que a História se tornasse objeto de estudo acadêmico. Ainda que a sua abordagem fosse teológica e

55 MÜLLER, 2017, p. 172, 179-180.

${ }^{56}$ MUNDHENK, Christine. Rhetorik und Poesie im Bildungssystem Philipp Melanchthons. In: BEUTEL, Albrecht (Ed.). Lutherjahrbuch. Göttingen: Vandenhoeck \& Ruprecht, 2011. v. 78, p. 263; cf. também MÜLLER, 2017, p. 165-166.

57 MUNDHENK, 2011, p. 275.

58 WIEDENHOFER, 1976, v. 1, p. 347-376. 
o acento do seu interesse fosse a exemplaridade moral fornecida pela História - e pelo estudo da Literatura antiga, que ele nela incluía -, a partir desse momento se abriu espaço para o desenvolvimento que o estudo da História pode vir a ter. ${ }^{59}$

\section{Considerações finais}

A pesquisa recente sobre Melanchthon mostra a importância da perspectiva prática para a compreensão de sua obra. $\mathrm{O}$ influxo do contexto humanista e o aspecto existencial presente na teologia luterana contribuíram para ele elaborar seu pensamento de forma que apresentasse uma finalidade pedagógica. A importância dada à retórica e sua relação íntima com a dialética são um elemento importante nessa estruturação. Linguagem, História e Literatura são temas que visam promover uma formação humanista. A distinção entre práxis e poiesis é extremamente útil para a clarificação do sentido prático que as pesquisa revelam em Melanchthon com vistas à apropriação contextual de seu pensamento.

Destacam-se como possibilidades para tal reapropriação:

- A atenção aos textos filosóficos de Melanchthon, principalmente sobre retórica, quanto à importância da linguagem para a prática compreensiva, pedagógica e política, conforme o seu contexto humanista.

- A superação da visão de Melanchthon como mero "pai da ortodoxia", entendendo a reformulação dos Loci durante toda a sua vida e até mesmo as modificações na Confessio augustana a partir de uma perspectiva aberta à revitalização constante do pensamento.

- O reconhecimento de que além de ser auxiliar importante de Lutero, Melanchthon mostra uma reflexão própria que valoriza a dimensão racional, a prática argumentativa e a preservação e transmissão do patrimônio cultural, sem o que nenhuma concepção emancipatória é possível.

\section{Referências}

BEISE ULRICH, Claudete; KLUG, João. Felipe Melanchthon (1497-1560): pedagogo da Reforma protestante, patrimônio da educação. Revista Brasileira de História das Religiões, Maringá: UEM, v. 8, n. 24, p. 149-170, jan./abr. 2016. Disponível em: <http://periodicos.uem.br/ojs/index. php/RbhrAnpuh/article/view/30706/16063>. Acesso em: 22 set. 2020.

FRANK, Günter. Die theologische Philosophie Philipp Melanchthons (1497-1560). Leipzig: Benno, 1995. (Erfurter Theologische Studien, Bd. 67).

. Praktische Philosophie unter den Bedingungen reformatorischer Theologie. Die Intellektlehre als Begründung der Willensfreiheit in Philipp Melanchthons Kommentaren zur praktischen Philosophie des Aristoteles. In: FRANK, Günter; LALLA, Sebastian (Hrgb.). Fragmenta Melanchthoniana. Band 1. Zur Geistesgeschichte des Mittelalters und der frühen Neuzeit. Heidelberg; Ubstadt-Weiher: Regionalkultur, 2003. p. 243-54.

${ }^{59}$ WIEDENHOFER, 1976, v. 1, p. 472-490; SCHNEIDER, Martin. Geschichte. In: FRANK (Ed.), 2017, p. 588. 
FRANK, Günter. Einleitung. In: MELANCHTHON, Philipp. Ethicae Doctrinae Elementa et Enarratio Libri quinti Ethicorum. Günter Frank (Hrgb.). Stuttgart-Bad Cannstatt: FrommannHolzboog, 2008. p. XIX-XLII.

. Topische Dogmatik im Zeitalter der Konfessionalisierung: Philipp Melanchthon, Wolfgang Musculus, Melchor Cano. In: DINGEL, Irene; KOHNLE, Armin (Hrsg.). Philipp Melanchthon: Lehrer Deutschlands, Reformator Europas. Leipzig: Evangelische Verlagsanstalt, 2011. p. 251-270.

. Einleitung. In: FRANK, Günter; MUNDT, Felix (Ed.). Der Philosoph Melanchthon. Berlin: De Gruyter, 2012. p. 1-10.

. Praktische Philosophie. In: FRANK, Günter (Ed.). Der Reformator zwischen Glauben und Wissen. Ein Handbuch. Berlin: De Gruyter, 2017. p. 457-467.

GROSS, Eduardo. A apreciação de literatura no humanismo teológico de Filipe Melanchthon. Pandaemonium Germanicum, São Paulo: USP, v. 23, n. 41, 2020, p. 95-124. Disponível em: http://www.revistas.usp.br/pg/article/view/172407/162009.

HOLM, Bo Kristian, Theologische Anthropologie. In: FRANK, Günter (Ed.). Der Reformator zwischen Glauben und Wissen. Ein Handbuch. Berlin: De Gruyter, 2017. p. 395-407.

MATZ, Wolfgang. Der befreite Mensch: Die Willenslehre in der Theologie Philipp Melanchthons. Göttingen: Vandenhoeck \& Ruprecht, 2001.

MAURER, Wilhelm. Der junge Melanchthon. Göttingen: Vandenhoeck \& Ruprecht, 19671969. 2 Bd.

MÜLLER, Ralf. Die Ordnung der Affekte: Frömmigkeit als Erziehungsideal bei Erasmus von Rotterdam und Philipp Melanchthon. Bad Heilbrunn: Julius Klinkhardt, 2017. (Tese apresentada na Faculdade de Psicologia e Pedagogia da Ludwig-Maximilians-Universität, Munique, 2015). MUNDHENK, Christine. Rhetorik und Poesie im Bildungssystem Philipp Melanchthons. In: BEUTEL, Albrecht (Ed.). Lutherjahrbuch. Göttingen: Vandenhoeck \& Ruprecht, 2011. v. 78, p. 251-275.

NEUMANN, Hans-Peter. Dialektik. In: FRANK, Günter (Ed.). Der Reformator zwischen Glauben und Wissen. Ein Handbuch. Berlin: De Gruyter, 2017. p. 515-534.

SCHNEIDER, Martin. Geschichte. In: FRANK, Günter (Ed.). Der Reformator zwischen Glauben und Wissen. Ein Handbuch. Berlin: De Gruyter, 2017. p. 577-590.

SPARM, Walter. Altes Reich. In: FRANK, Günter (Ed.). Der Reformator zwischen Glauben und Wissen. Ein Handbuch. Berlin: De Gruyter, 2017. p. 611-646.

WEAVER, William P. Rhetorik. In: FRANK, Günter (Ed.). Der Reformator zwischen Glauben und Wissen. Ein Handbuch. Berlin: De Gruyter, 2017. p. 535-546.

WENGERT, Timothy J. Human Freedom, Christian Righteousness: Philip Melanchthon's Exegetical Dispute with Erasmus of Rotterdam. New York; Oxford: Oxford University Press, 1998. WESTHELLE, Vítor. Pressupostos e implicações do conceito de práxis em Hugo Assmann. Estudos Teológicos, v. 21, n. 1, p. 7-31, 1981.

. Clashes of Confession: The Case of Latin America in a Global Context. Currents in Theology and Mission, v. 34, n. 4, p. 293-300, Aug. 2008a.

. Uma "teoria" da cruz. As artes humanas: poiesis, praxis e theoria. In: . O Deus escandaloso: O uso e abuso da cruz. São Leopoldo: EST; Sinodal, 2008b. capítulo 8. WIEDENHOFER, Siegfried. Formalstrukturen humanistischer und reformatorischer Theologie bei Philipp Melanchthon. Bern: Herbert Lang; Frankfurt a. M.; München: Peter Lang, 1976. Teil 1: Text. Teil 2: Anmerkungen und Literaturverzeichnung. (Regensburger Studien zur Theologie). WRIEDT, Markus. Bildung, Schule und Universität. In: FRANK, Günter (Ed.). Der Reformator zwischen Glauben und Wissen. Ein Handbuch. Berlin: De Gruyter, 2017. p. 141-154. 